\title{
Quantitative analysis of macro steel fiber influence on crack geometry and water permeability of concrete
}

\author{
Yining Ding ${ }^{\text {a, }}$, Dong $\mathrm{Li}^{\mathrm{a}}$, Yulin Zhang ${ }^{\mathrm{b}}$ \\ ${ }^{\mathrm{a}}$ State Key Laboratory of Coastal and Offshore Engineering, Dalian University of Technology, Dalian 116024, \\ China \\ ${ }^{\mathrm{b}}$ Centre of Mathematics, University of Minho, Braga 4700-052, Portugal
}

\begin{abstract}
In this work, the water permeability of the cracked concrete has been investigated. Three types of cylindrical specimens with different fiber content were pre-cracked by the feedback controlled splitting test, and the specimens without any fiber reinforcement were also studied as reference. The water permeability of the specimens with different crack width were measured by hydraulic permeability test. The coordinate data of the crack surface was collected by the self designed data acquisition system, the total crack length and surface area of the samples were analyzed, the crack geometry (tortuosity and roughness) was evaluated quantatively. A modified factor $\xi$ was introduced to the Poiseuille law to verify the permeability of the cracked specimen. The results showed that with the addition of macro steel fibers, the deformability of the specimens was improved significantly and the crack width could be controlled. The coefficient of the water permeability of the specimens was declined by fiber addition, the modified Poiseuille law could be used to evaluate the water permeability of the cracked concrete, the modified factor $\xi$ decreased with the increasing of fiber dosage. The crack tortuosity and surface roughness increased obviously with the addition of steel fiber.
\end{abstract}

Keywords: cracked concrete; steel fiber; water permeability; crack tortuosity; surface roughness

\section{Introduction}

The water permeability plays a significant role in the serviceability and durability of concrete. Currently, the water permeability of the concrete is measured by the penetration test of un-cracked

\footnotetext{
${ }^{*}$ Corresponding author. Tel.: +86 41184709756.

E-mail address: ynding@ hotmail.com (Y. Ding).
} 
concrete based on different guidelines [1-3]. Concrete before cracking is mainly in the elastic stage, and the water tightness before cracking depends mainly on the porosity and density of concrete and can be evaluated by the penetration depth. However, in the practice, all the reinforced concretes work with cracks in the service stage due to the low tensile capacity of the concrete. The existence of the cracks (especially in the underground structure) can obviously accelerate the penetration rate of the moisture and other hazardous substances into concrete. The investigation on the water permeability of cracked concrete, especially the fiber effect on the permeability of cracked concrete in the service stage is still very limited.

Fiber reinforced concrete (FRC) is an increasingly popular construction material. The FRC shows higher toughness than plain concrete without any reinforcement under static load, such as compression, tension, bending and shear [4-14]. The addition of fibers can enhance the energy absorption capacity of the cementitious materials under dynamic load, such as impact and blast [1520].

Some investigations have been conducted to evaluate the effect of cracks on water permeability of cementitious materials [21-23]. The important first step is to prefabricate the crack in different widths using feedback controlled splitting test. Wang et al [24] studied the permeability of concrete with various crack widths, and evaluated the effect of the crack opening displacement (COD) on the permeability coefficient of specimens. The results showed that when the COD was less than $50 \mu \mathrm{m}$, there was no obvious increment in permeability coefficient. With the increasing of the COD from $50 \mu \mathrm{m}$ up to $200 \mu \mathrm{m}$, the permeability coefficient of the cracked specimen increased rapidly. When the COD was greater than $200 \mu \mathrm{m}$, the increasing rate of permeability declined obviously and became steady. Aldea et al [25] investigated the influence of different cementitious composites (paste, mortar, normal and high strength concrete), sample size and crack width of the sample on the permeability, the experimental results indicated that the water permeability was significantly affected by the type of the matrix and the crack width of the samples, whereas the sample thickness had little effect on the 
permeability. Yi et al [23] analyzed the effect of hydraulic pressure on permeability of the cracked concrete specimens, and the results suggested that the allowable crack width for concrete structures should consider the effects of the exposed hydraulic pressure conditions. Akhavan et al [22] investigated the influence of crack width, tortuosity and roughness on water permeability of mortar, and correlated the relationship between the crack geometry and the water permeability coefficient. Rastiello et al [26] studied the real-time water permeability evolution of cracked concrete specimens under loading, and estimated the water permeability by relating in real-time flow measurements and geometrical information. For FRC, Rapoport et al [27] evaluated the relationship between the permeability coefficient and the crack width of the steel fiber reinforced specimen. Picandet et al [28] reported the effect of steel fiber reinforcement on water permeability of high strength concrete (compressive strength $130 \mathrm{MPa}$ ). However, it is clear from the literature review that there is still a lack of a systematic investigation of the fiber effect on the crack tortuosity, roughness and permeability as well as on the relationship between crack geometry and water permeability of macro steel fiber reinforced normal strength concrete.

In order to analyze the influence of macro steel fiber on water permeability of the cracked concrete, a series of tests were carried out: (a) the feedback controlled splitting test was adopted to prefabricate different crack width, (b) a self designed set-up was used to evaluate the water permeability of the cracked specimen, (c) an invented laser scanner equipment was introduced to obtain the coordinate data of the crack surface. The splitting tensile properties of the specimens with different fiber dosage were analyzed, the coefficient of water permeability of the specimens was compared, and the effect of macro steel fiber on the crack tortuosity and surface roughness was studied. The Poiseuille law was modified by considering the effect of crack geometry (tortuosity and roughness) on the permeability.

In an uni-directional situation (ignoring gravity effects), the permeability of a crack can be assessed as [22, 29]: 


$$
k=\frac{Q}{A} \frac{\mu}{\rho}\left(\frac{\Delta p}{\Delta x}\right)^{-1}
$$

Where: $k$ is the permeability coefficient of the crack, $\mathrm{m}^{2} ; Q$ is the volume of water flow, $\mathrm{m}^{3} / \mathrm{s} ; \mathrm{A}$ is the cross-section area to flow, $\mathrm{m}^{2} ; \mu$ is the water dynamic viscosity, $0.001 \mathrm{~Pa} \bullet \mathrm{s} ; \rho$ is the density of the water, $998 \mathrm{~kg} / \mathrm{m}^{3} ; \Delta p / \Delta x$ is the pressure gradient, $\mathrm{Pa} / \mathrm{m}$.

The Poiseuille law (also referred as parallel plate model) is a popular model to evaluate the incompressible fluid flow through a single crack. For this model, the permeability coefficient of the crack can be identified as [29]:

$$
k=\frac{b^{2}}{12}
$$

Where $b$ is the crack width, m.

Eqs. (2) is strictly valid for a smooth, parallel plate. In fact, surface of the real crack in concrete is usually rough and tortuous, and such roughness and tortuosity of the crack may reduce the water permeability. Some researchers have adopted this model to verity the flow of the cracked concrete $[22,26,28]$. In order to account for this reduction in permeability, a modified factor $\xi$ regarding the effect of the crack geometry has been introduced (Eq.(3)).

$$
k=\xi \frac{b^{2}}{12}
$$

Akhavan et al [22] reported that the value of $\xi$ could be about 0.229 and 0.163 for plain and polypropylene fiber reinforced mortar, respectively. For high strength concrete reinforced with macro steel fiber (compression strength 130MPa), the value of $\xi$ could be about 0.01 [28]. The effect of macro steel fiber on the crack tortousity and surface roughness of normal strength concrete is rare investigated.

\section{Experimental program}

A series of experiments had been carried out. Three groups of water permeability test were conducted on macro steel fiber reinforced concrete varying with fiber contents, and one group water 
permeability test of plain concrete matrix was also performed as reference. Other parameters, such as strength of concrete and size of specimen were kept constant throughout the whole program.

\subsection{Materials}

In this program, the base mix design of concrete without fiber reinforcement was as follows: cement $\mathrm{P} \cdot \mathrm{O}$ 42.5R $472.8 \mathrm{~kg} / \mathrm{m}^{3}$, Silica fume $37.8 \mathrm{~kg} / \mathrm{m}^{3}$; fine aggregate $827.5 \mathrm{~kg} / \mathrm{m}^{3}(0-5 \mathrm{~mm})$, coarse aggregate $827.5 \mathrm{~kg} / \mathrm{m}^{3}(5-15 \mathrm{~mm})$; water $222.2 \mathrm{~kg} / \mathrm{m}^{3}$; water binder ratio 0.43 , Super plasticizer (SP) $5.7 \mathrm{~kg} / \mathrm{m}^{3}$ (1.1\% of the binder). The widely used macro steel fibers (Fig.1) were added into the concrete samples. The parameters of the fibers were illustrated in Table 1 and the fiber dosage was 25,35 and $55 \mathrm{~kg} / \mathrm{m}^{3}$, respectively.

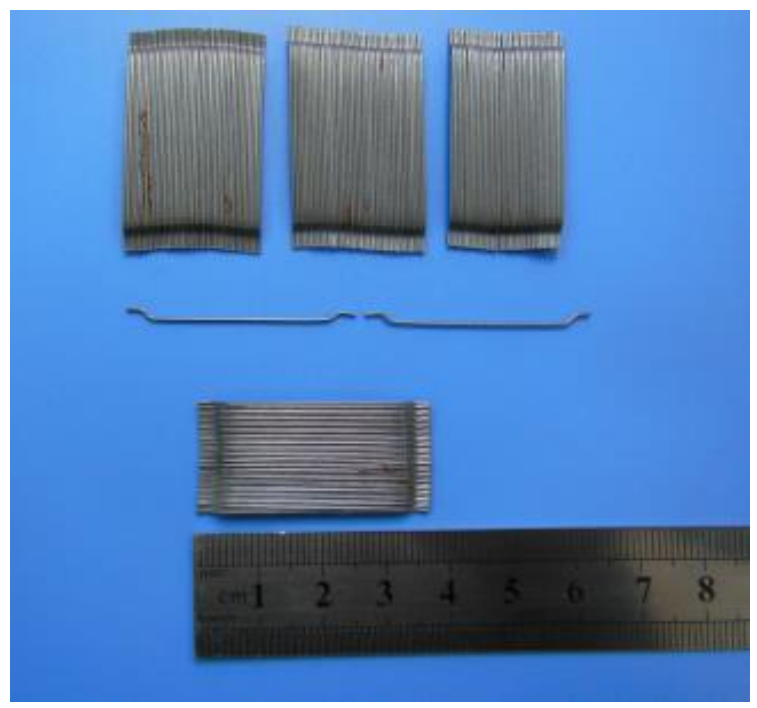

Fig.1 Macro steel fibers

Table 1 Properties of the macro steel fiber

\begin{tabular}{lcccccc}
\hline Type & $\begin{array}{c}\text { Length } \\
(\mathrm{mm})\end{array}$ & $\begin{array}{c}\text { Diameter } \\
(\mathrm{mm})\end{array}$ & $\begin{array}{c}\text { Aspect } \\
\text { ratio }\end{array}$ & $\begin{array}{c}\text { Tensile strength } \\
(\mathrm{MPa})\end{array}$ & $\begin{array}{c}\text { E-Modulus } \\
(\mathrm{GPa})\end{array}$ & $\begin{array}{c}\text { Number } \\
(\mathrm{Pieces} / \mathrm{kg})\end{array}$ \\
\hline macro steel fiber & 35 & 0.54 & 65 & 1345 & 200 & 14500 \\
\hline
\end{tabular}

\subsection{Test specimens}

The cylindrical specimens were used in this work. Each type of samples was cast into $100 \mathrm{~mm}$ diameter $\times 250 \mathrm{~mm}$ height cylinders, which was de-molded after $24 \mathrm{~h}$ and kept in a standard curing room for 28 days. Before experiment, the diamond blade saw was introduced and the cylinders were cut to obtain $40 \mathrm{~mm}$ thick specimens. Ten samples were simultaneously prepared for each type of 
concrete. In order to measure the crack width at different positions, each face of the specimens were painted with white color [26].

\subsection{Feedback controlled splitting test}

The feedback controlled splitting test was illustrated in Fig.2. The LVDT was fixed on each side of the specimen to monitor the crack opening displacement (COD). In order to avoid the stress concentration underneath the loading points, two pieces of plywood were placed between the loading plate and the specimen. The deformation rate was about $0.02 \mathrm{~mm} / \mathrm{min}$. When the average displacement of the two sides reached a predetermined value (about 50, 100, 150, 200, 250,300 $\mu \mathrm{m}$ ), the test samples were unloaded.

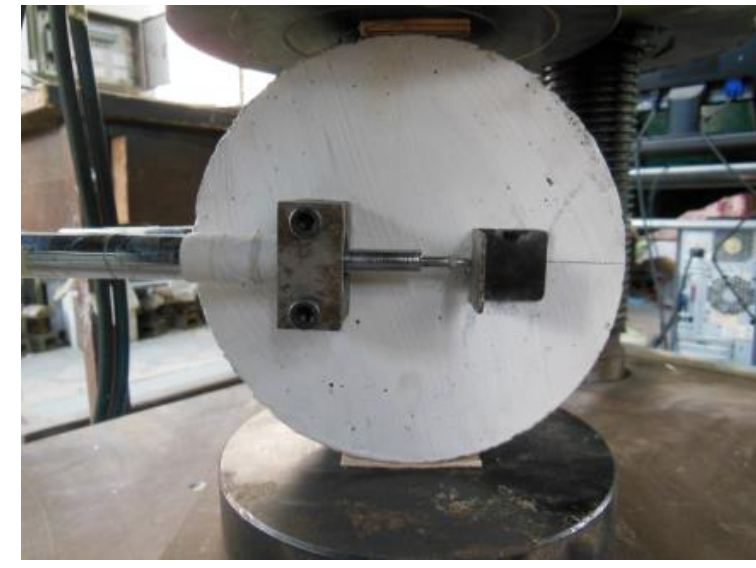

(a)

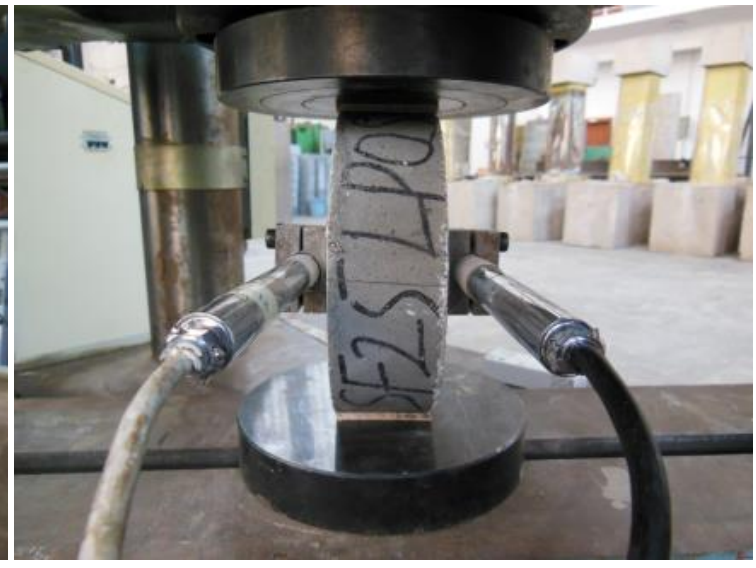

(b)

Fig.2 Feedback controlled splitting test: (a) front face; (b) lateral face

\subsection{Effective crack width}

The crack width varied at different points along the cracked sample, in order to build a prediction model for water permeability, the effective crack width should be considered [26]. A device named Supereyes with 500× magnification was used to measure the crack width at different points after unloading (as shown in Fig.3). 


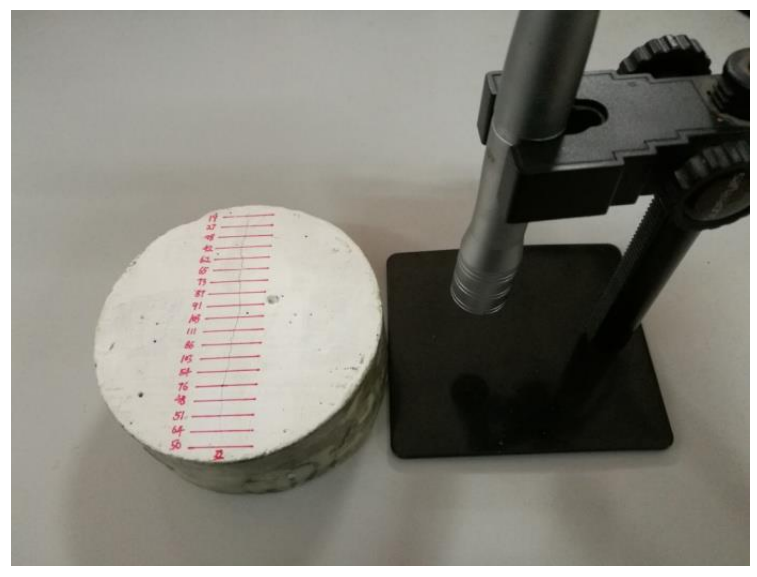

Fig.3 Supereyes

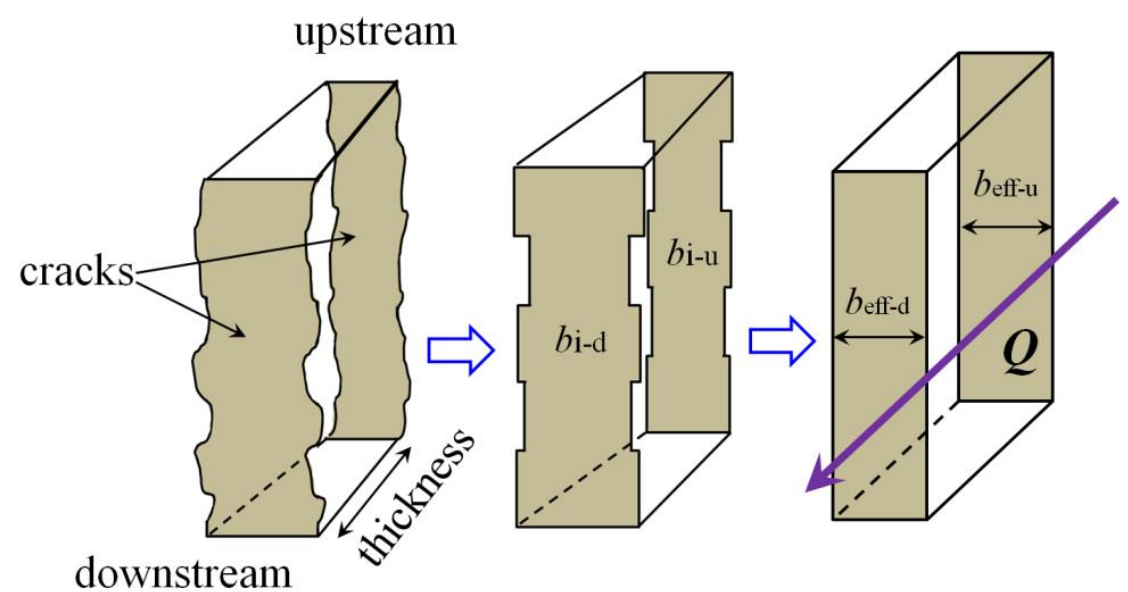

Fig.4 Computational method for the effective crack width [22, 26]

Fig.4 shows the equivalent procedure of a crack and the effective crack width of a sample can be calculated as follows $[22,26,30]$ :

$$
b_{\text {eff-u/d }}=\sqrt[3]{\frac{1}{n} \sum_{i=1}^{n} b_{\mathrm{i}-\mathrm{u} / \mathrm{d}}^{3}}
$$

Where $b_{\text {eff-u/d }}$ is the effective crack width of the upside/downside face; $b_{\mathrm{i}-\mathrm{u} / \mathrm{d}}$ represents the crack width of the measured $i$ point of the upside/downside face; $n$ represents the number of the measured points. The effective crack width of the specimen can be computed via

$$
b_{\text {eff }}=\frac{b_{\text {eff }-\mathrm{u}}+b_{\text {eff }-\mathrm{d}}}{2}
$$

Where $b_{\text {eff }}$ means the effective crack width of the specimen; $b_{\text {eff-u }}$ means the effective crack width of the upside face; $b_{\text {eff-d }}$ means the effective crack width of the downside face. 


\subsection{Water permeability test}

For the permeability test, an equipment was developed with two steel vessels and a water pump [26]. The inlet/outlet pipes are connected to the steel vessels and the pump. During the permeability test, two steel vessels were fixed on the faces of the specimen, and the water pump offered a steady water pressure of $0.1 \mathrm{MPa}$. The whole hydraulic test was shown in Fig. 5.

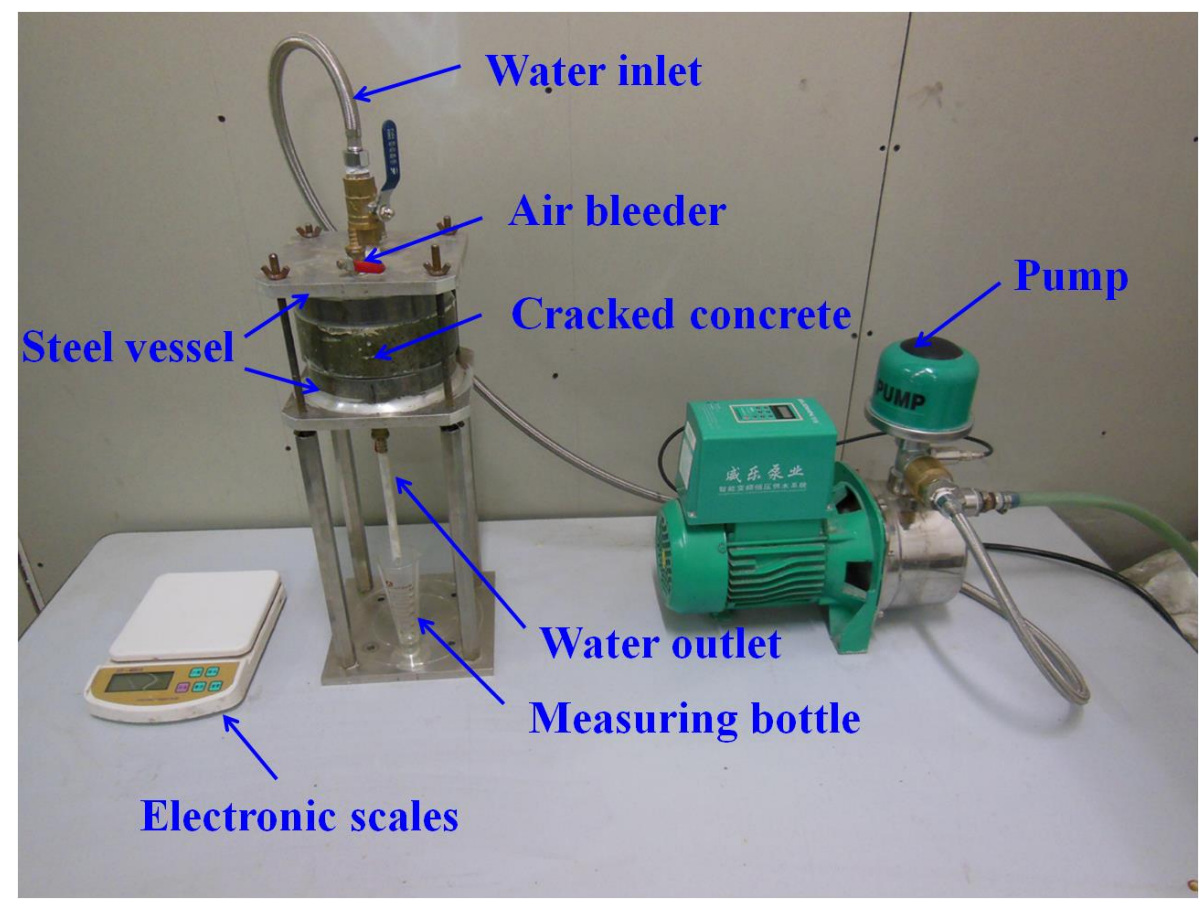

Fig.5 Hydraulic permeability test for cracked concrete

In order to avoid the influence of self-healing on measurements, the permeability coefficient was calculated from the water flow percolating during the first minutes only [28]. The test was carried out in controlled temperature conditions $\left(20 \pm 1^{\circ} \mathrm{C}\right)$. During the test, the water flowed into the beaker and the mass of water out was monitored.

\subsection{Acquisition of the surface data}

After the permeability test, a V-shaped mouth was made and the specimen was split into two pieces along the crack, as shown in Fig.6, and the fractured surfaces were adopted to evaluate the crack tortuosity and surface roughness, the steel fibers of the surface were cut with the needle-nosed pliers. A self-designed equipment was used for data acquisition (see Fig.7). 


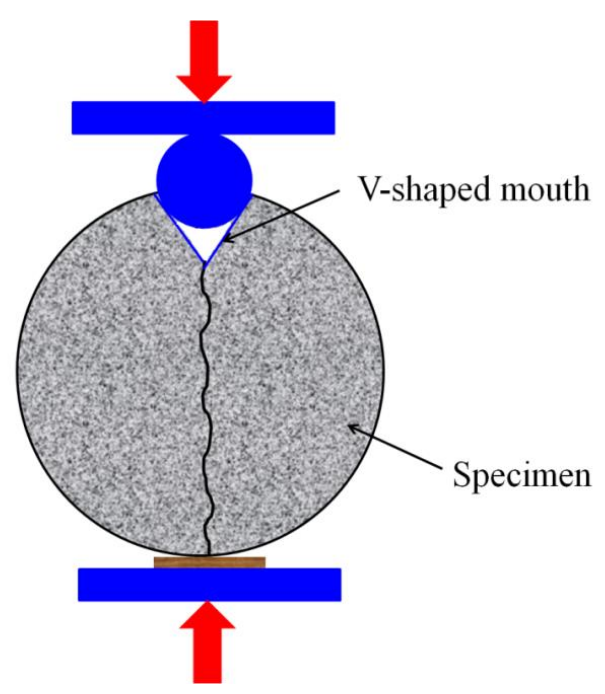

Fig.6 Splitting the specimen

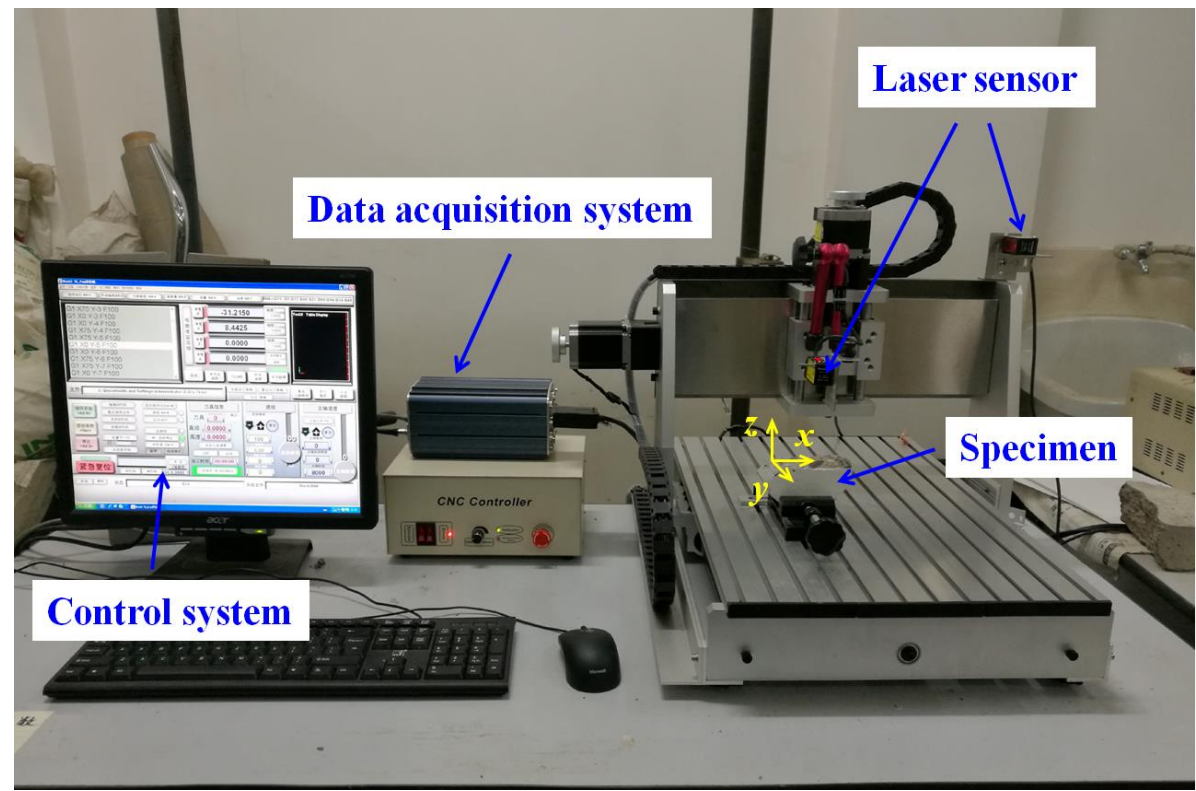

Fig.7 Data acquisition system

The movement of the specimen is controlled according to a scan path (Fig.8). The interval of the $\mathrm{y}$-axis is $0.5 \mathrm{~mm}$.

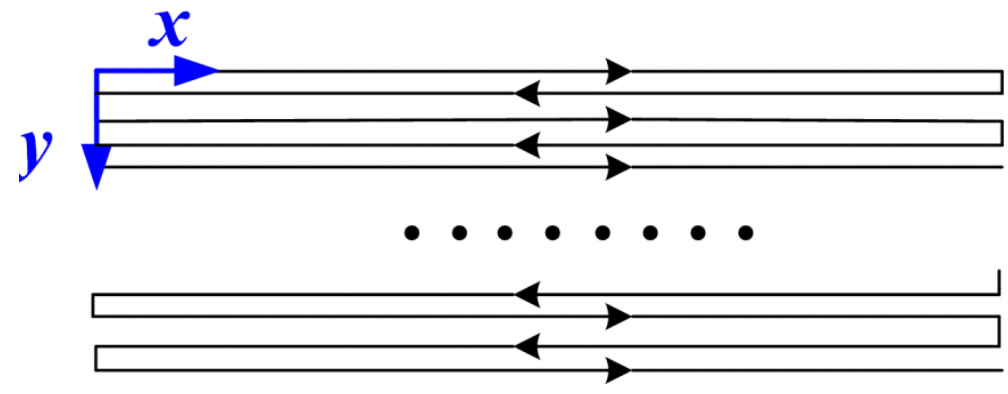

Fig.8 Scan path 
The crack tortuosity $(\tau)$ and roughness $\left(R_{\mathrm{s}}\right)$ can be defined as follows [22, 31]:

$$
\begin{aligned}
& \tau=\left(\frac{L_{0}}{L_{\mathrm{t}}}\right)^{2} \\
& R_{\mathrm{s}}=\frac{S_{\mathrm{t}}}{S_{0}}
\end{aligned}
$$

Where the $L_{\mathrm{t}}$ is the total crack length, $L_{0}$ is the projected crack length, $S_{\mathrm{t}}$ is the total surface area of the crack, $S_{0}$ is the projected area of the crack.

The method of calculating the projected crack length and the total crack length is demonstrated in Fig.9.

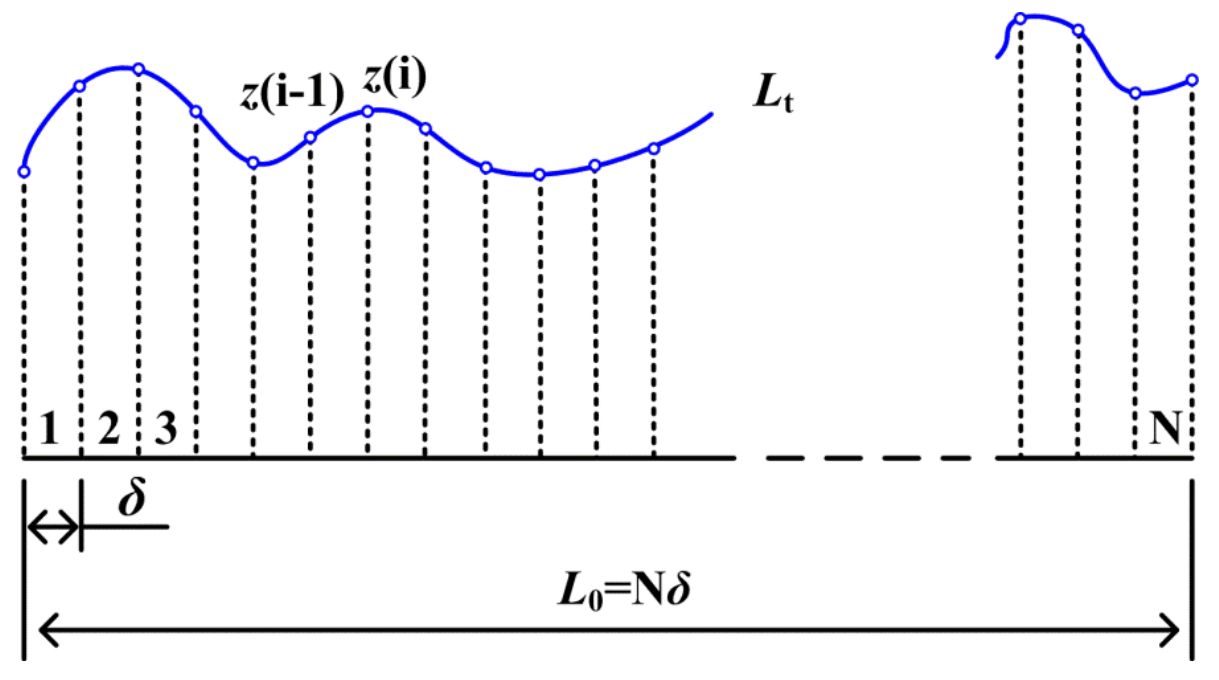

Fig.9 Explanation of the total crack length and the projected crack length

The total crack length $L_{\mathrm{t}}$ can be determined as follows:

$$
L_{\mathrm{t}}=\sum_{\mathrm{i}=1}^{\mathrm{N}} \sqrt{[z(\mathrm{i})-z(\mathrm{i}-1)]^{2}+\delta^{2}}
$$

Where $\mathrm{z}(\mathrm{i}), \mathrm{z}(\mathrm{i}-1)$ are the height corresponding to the point $\mathrm{i}$ and $\mathrm{i}-1$, respectively; $\delta$ means the size of the element, $\mathrm{N}$ means the number of the element.

The total surface area $S_{\mathrm{t}}$ is determined by the projective covering method [32-33], the schematic view of this method is shown in Fig.10. 


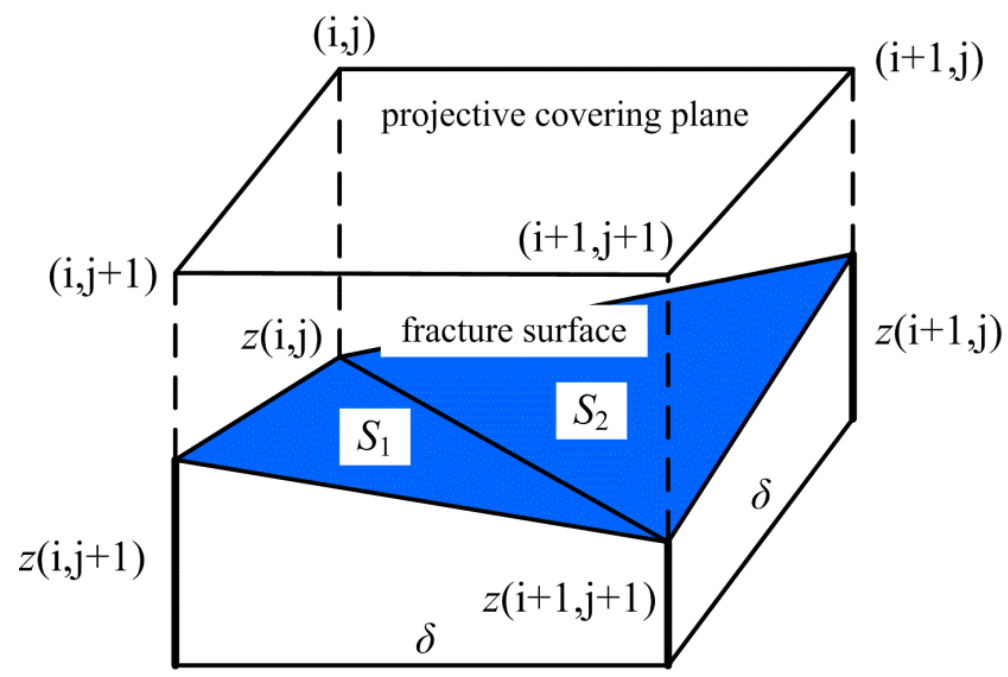

Fig.10 Projective covering method [33]

In Fig.10, the $z(i, j), z(i+1, j), z(i, j+1)$ and $z(i+1, j+1)$ are the height corresponding to the $(i, j)$, $(\mathrm{i}+1, \mathrm{j}),(\mathrm{i}, \mathrm{j}+1)$ and $(\mathrm{i}+1, \mathrm{j}+1)$, respectively. The area $S_{1}$ of the triangle can be calculated according to the Heron's formula in Eq. (9).

$$
S_{1}=\sqrt{l_{1}\left(l_{1}-a_{1}\right)\left(l_{1}-b_{1}\right)\left(l_{1}-c_{1}\right)}
$$

Where $l_{1}$ is half of the perimeter of the triangle, $a_{1}, b_{1}, c_{1}$ are the triangle side length, respectively. The $l_{1}, a_{1}, b_{1}$ and $c_{1}$ can by calculated via

$$
\begin{gathered}
l_{1}=\frac{1}{2}\left(a_{1}+b_{1}+c_{1}\right) \\
a_{1}=\sqrt{[z(\mathrm{i}, \mathrm{j})-z(\mathrm{i}, \mathrm{j}+1)]^{2}+\delta^{2}} \\
b_{1}=\sqrt{[z(\mathrm{i}, \mathrm{j}+1)-z(\mathrm{i}+1, \mathrm{j}+1)]^{2}+\delta^{2}} \\
c_{1}=\sqrt{[z(\mathrm{i}, \mathrm{j})-z(\mathrm{i}+1, \mathrm{j}+1)]^{2}+2 \delta^{2}}
\end{gathered}
$$

Similarly, the area $S_{2}$ of another triangle can be determined. The surface area $S_{\mathrm{i}, \mathrm{j}}$ of the cell $(\delta \times \delta)$ is given by

$$
S_{\mathrm{i}, \mathrm{j}}=S_{1}+S_{2}
$$

The total surface area $S_{\mathrm{t}}$ of the cracked specimen may be estimated by Eq.(15) 


$$
S_{\mathrm{t}}(\delta)=\sum_{\mathrm{i}, \mathrm{j}=1}^{N(\delta)} S_{\mathrm{i}, \mathrm{j}}
$$

The procedures for calculating of the $\tau$ and the $R_{\mathrm{s}}$ were carried out through MATLAB programming codes.

\section{Results and discussion}

\subsection{Compressive strength}

Three cubic specimens with $150 \times 150 \times 150 \mathrm{~mm}$ were cast to investigate the compressive strength. The mean values of compressive strength $f_{\text {cu }}$ at the age of $28 \mathrm{~d}$ are listed in Table 2 . As expected, the addition of macro steel fiber has little influence on compressive strength of the matrix $[18,34-35]$.

Table 2 Different fiber contents and the compression strength

\begin{tabular}{lcc}
\hline Matrix type & $\begin{array}{c}\text { steel fiber } \\
\left(\mathrm{kg} / \mathrm{m}^{3}\right)\end{array}$ & $\begin{array}{c}f_{\text {cu }} \\
(\mathrm{MPa})\end{array}$ \\
\hline NC & 0 & 52.9 \\
SFRC25 & 25 & 52.4 \\
SFRC35 & 35 & 54.4 \\
SFRC55 & 55 & 51.4 \\
\hline
\end{tabular}

\subsection{Splitting tensile properties}

Fig.11 illustrates the comparison of the load-COD curves of the specimens with different fiber dosage.

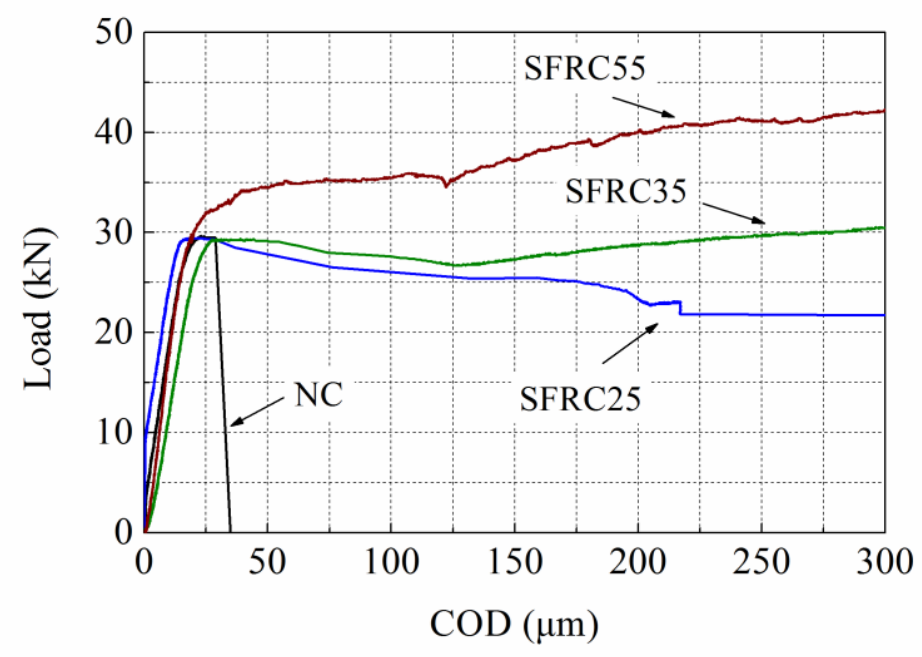

Fig.11 Comparison of load-COD curves of different specimens

From Fig.11, it can be seen that: 
i) For the NC specimen, the appearance of the crack and the failure of the specimen take place simultaneously, and the crack width of the specimens without any fiber reinforcement is hardly to control.

ii) For the macro steel fiber reinforced specimens, SFRC25, SFRC35 and SFRC55 indicate relative stable post-crack behavior. After the cracking, the steel fibers continue to transmit tensile stresses across the crack in the concrete and prevent the further spread of cracks, so that the crack width can be controlled more easily than the NC specimens.

\subsection{Relationships between effective crack width and permeability}

Due to the brittle properties of the concrete without any reinforcement, a combined method is adopted for the NC specimens, the two pieces could be combined by the iron belt after the splitting test $[23,36-37]$.

Fig.12 shows the comparison of the experimental data and the curves predicted by the Poiseuille law. The comparison of the experimental value and the theoretical value at different effective crack width is shown in Table 3.

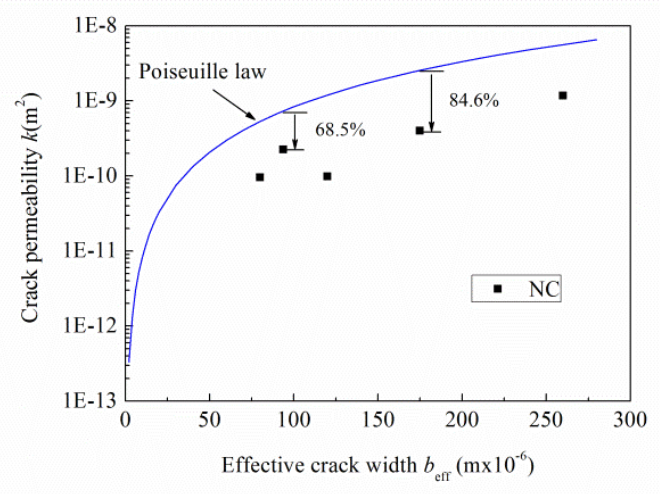

(a)

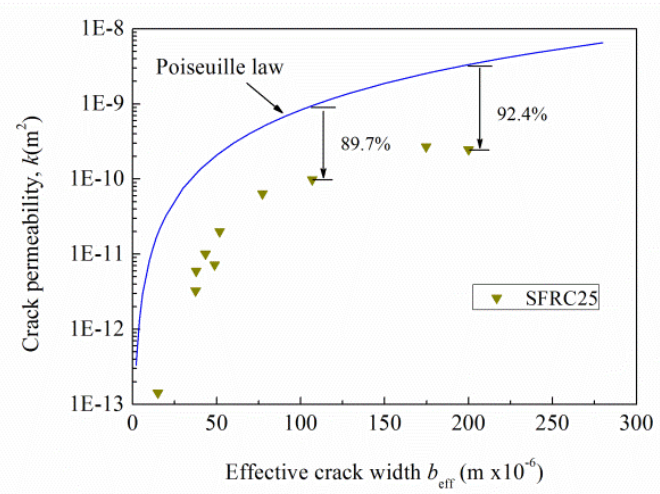

(b) 


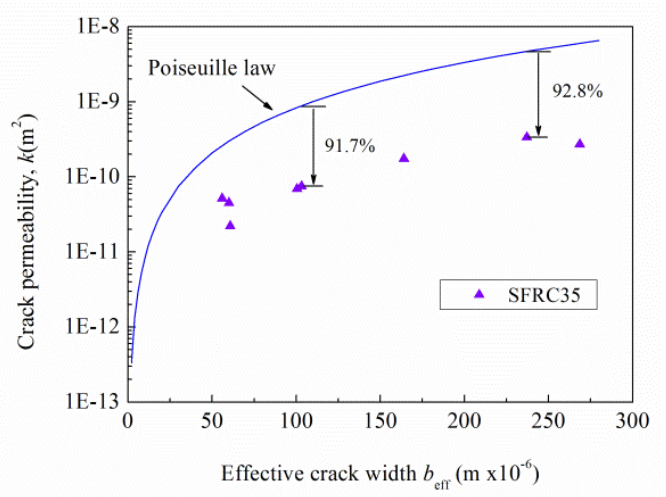

(c)

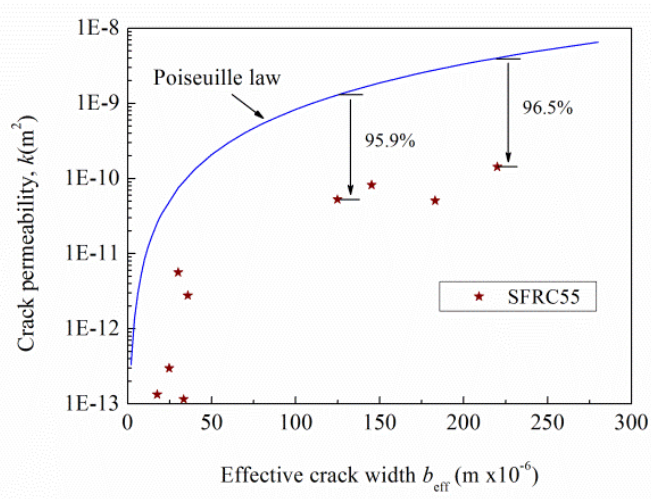

(d)

Fig.12 Theoretical and experimental values of water permeability of different cracked specimens: (a) NC; (b) SFRC25; (c) SFRC35; (c) SFRC55

Table 3 Comparison of the experimental value and theoretical value of water permeability

\begin{tabular}{|c|c|c|c|c|c|c|c|c|}
\hline \multirow{2}{*}{$\begin{array}{l}\text { Effective } \\
\text { crack width }\end{array}$} & \multicolumn{4}{|c|}{ About $100 \mu \mathrm{m}$} & \multicolumn{4}{|c|}{ About $200 \mu \mathrm{m}$} \\
\hline & $\begin{array}{c}\mathrm{NC} \\
(93.8) \\
\end{array}$ & $\begin{array}{l}\text { SFRC25 } \\
(106.9)\end{array}$ & $\begin{array}{c}\text { SFRC35 } \\
(103.2) \\
\end{array}$ & $\begin{array}{c}\text { SFRC55 } \\
(124.8) \\
\end{array}$ & $\begin{array}{c}\mathrm{NC} \\
(175.2) \\
\end{array}$ & $\begin{array}{l}\text { SFRC25 } \\
(200.1)\end{array}$ & $\begin{array}{c}\text { SFRC35 } \\
(237.1) \\
\end{array}$ & $\begin{array}{c}\text { SFRC55 } \\
(220.0) \\
\end{array}$ \\
\hline $\begin{array}{l}\text { Theoretical } \\
\text { value } / \mathrm{m}^{2}\end{array}$ & 7.3E-10 & 9.5E-10 & 8.9E-10 & $1.3 \mathrm{E}-9$ & 2.6E-9 & $3.3 \mathrm{E}-9$ & 4.7E-9 & 4.0E-9 \\
\hline $\begin{array}{l}\text { Experimental } \\
\text { value } / \mathrm{m}^{2}\end{array}$ & $2.3 \mathrm{E}-10$ & $9.8 \mathrm{E}-11$ & 7.4E-11 & $5.3 \mathrm{E}-11$ & $4.0 \mathrm{E}-10$ & $2.5 \mathrm{E}-10$ & $3.4 \mathrm{E}-10$ & $1.4 \mathrm{E}-10$ \\
\hline
\end{tabular}

Note: the value in () is the effective crack width corresponding to the specimen.

From Fig.12 and Table 3, it can be seen that:

i) The measured water permeability under different effective crack width of all the cracked specimens is below the predicted value calculated by the Poiseuille law.

ii) When the effective crack width reaches to about $100 \mu \mathrm{m}$, the coefficients of the measured water permeability of NC, SFRC25, SFRC35, SFRC55 are 2.3E-10, 9.8E-11, 7.4E-11 and 5.3E-11 $\mathrm{m}^{2}$, respectively, compared to the corresponding theoretical values, the test results of NC, SFRC25, SFRC35, SFRC55 decrease by about $68.5 \%, 89.7 \%, 91.7 \%$ and $95.9 \%$, respectively.

iii) When the effective crack width reaches to about $200 \mu \mathrm{m}$, the coefficients of the water permeability of NC, SFRC25, SFRC35, SFRC55 are 4.0E-10, 2.5E-10, 3.4E-10 and 1.4E$10 \mathrm{~m}^{2}$, respectively, compared to the corresponding theoretical values, the test results of $\mathrm{NC}$, 
SFRC25, SFRC35, SFRC55 decrease by about 84.6\%, 92.4\%, 92.8\% and 96.5\%, respectively.

From the discussion above, it can be summarized that the water permeability of the cracked concrete is not conformed to the Poiseuille law for smooth, straight, and parallel plate. The influence of the crack tortuosity and surface roughness on water permeability should be considered.

Fig.13 illustrates the relationship between the effective crack width and the crack permeability. The fitted parameter $\xi$ and the correlation coefficient $R^{2}$ of all the cracked specimens with different fiber contents are listed in Table 4. The correlation coefficients of all the specimens vary between 0.828 and 0.950 .

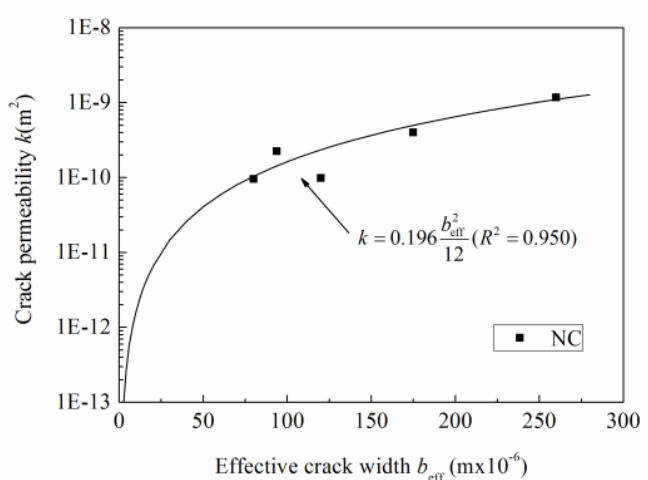

(a)

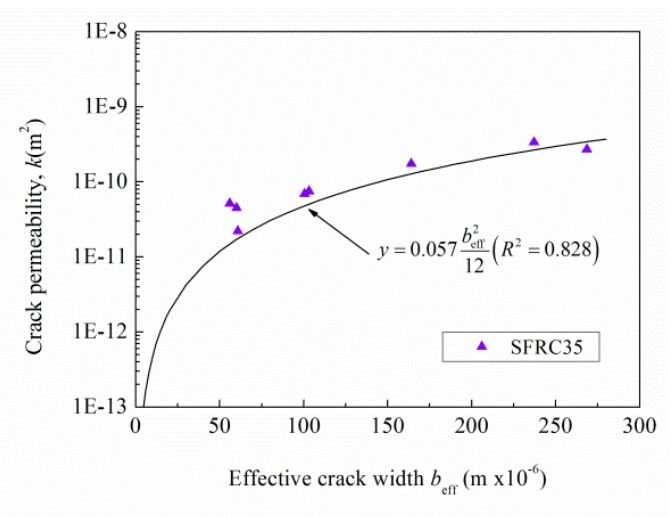

(c)

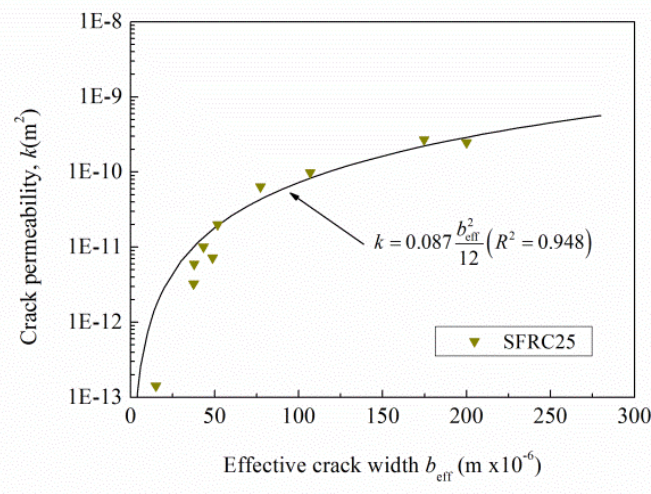

(b)

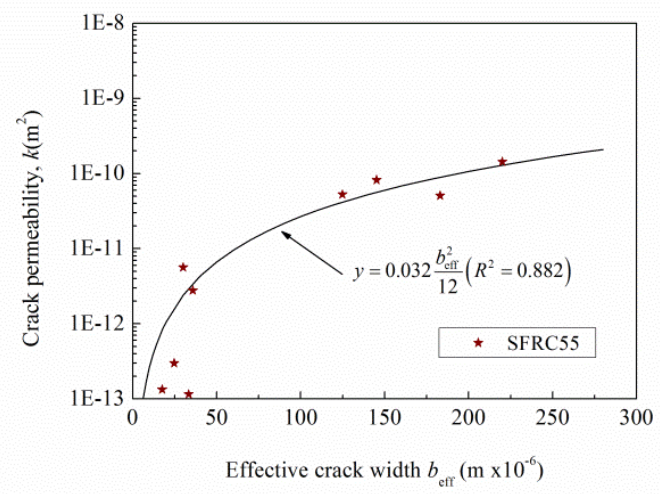

(d)

Fig.13 Relationship of the water permeability and the effective crack width of (a) NC, (b) SFRC25, (c) SFRC35, (d) SFRC55 
Table 4 Fitted parameters

\begin{tabular}{lcc}
\hline Matrix type & $\xi$ & $R^{2}$ \\
\hline NC & 0.196 & 0.950 \\
SFRC25 & 0.081 & 0.948 \\
SFRC35 & 0.057 & 0.828 \\
SFRC55 & 0.032 & 0.882 \\
\hline
\end{tabular}

From Fig.13 and Table 4, it can be seen that:

i) The $R^{2}$ of the four types of specimens are higher than 0.800 . Hence, the relationship between the effective crack width and the crack permeability of all the specimens corresponds well with the modified Poiseuille law (Eq.(3)).

ii) Compared to the NC specimen, the modified index $\xi$ of SFRC25, SFRC35 and SFRC55 decrease by about $56 \%, 71 \%$ and $84 \%$, respectively.

iii) Compared to the SFRC25 specimen, the modified index $\xi$ of SFRC35 and SFRC55 decrease by about $30 \%$ and $60 \%$, respectively.

The discussion above demonstrates that the modified Poiseuille law can be adopted to character the permeability of the cracked concrete with and without macro steel fiber reinforcement. In other words, the water permeability is a function of effective crack width with square regarding to the effect of crack tortuosity and surface roughness. The modified index $\xi$ is affected by the addition of steel fiber, and the $\xi$ decreases with the increasing of fiber dosage. The macro steel fibers may change the crack geometry.

\subsection{Crack tortuosity and surface roughness}

Fig. 14 shows the $3 \mathrm{D}$ view of the cleft crack surface of $\mathrm{NC}$ specimen and $35 \mathrm{~kg} / \mathrm{m}^{3}$ steel fiber reinforced specimen, respectively. 


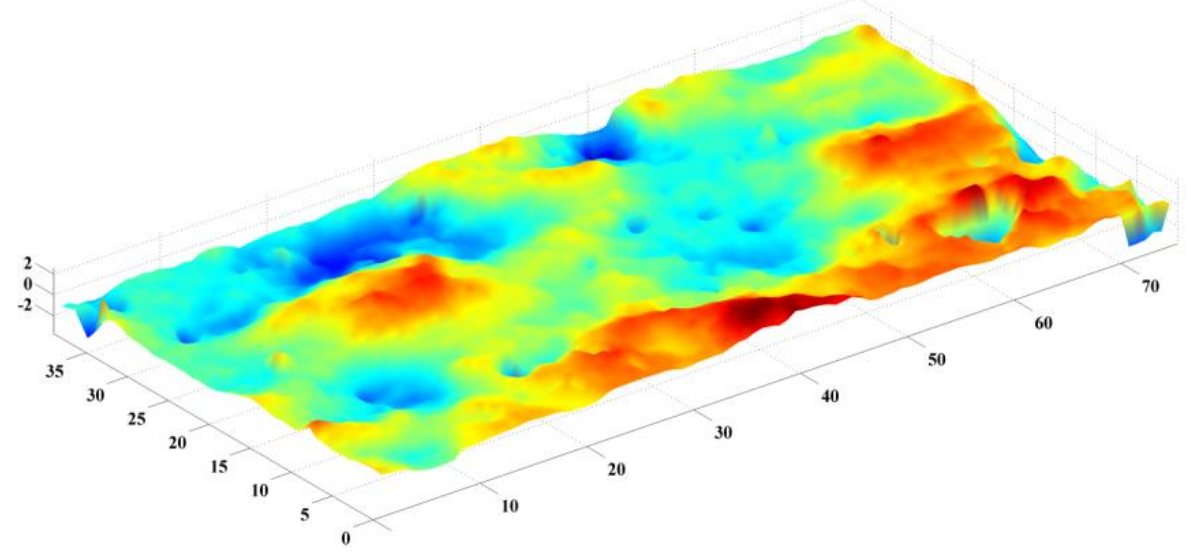

(a)

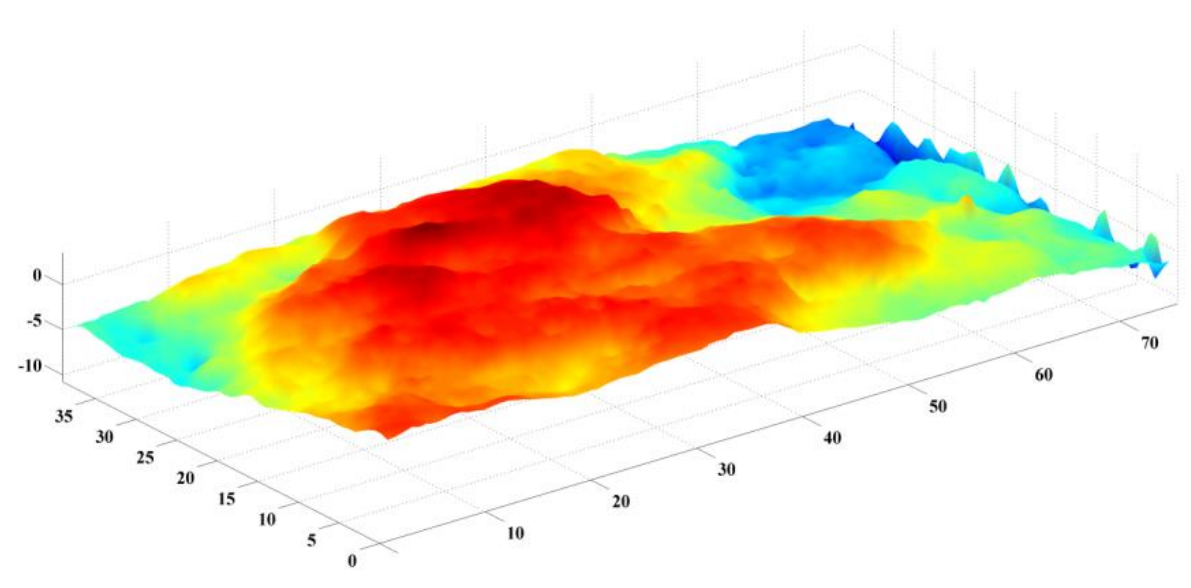

(b)

Fig.14 Crack surface reconstruction: (a) NC specimen; (b) SFRC35 specimen

The 3D presentation is an important complement to the surface roughness evaluation [38-41]. From Fig.14, it can be seen that the height difference of the surface of fiber reinforced concrete is much greater than that of the NC specimen. With the addition of steel fibers, a much larger total crack length and total surface area are created.

The statistical analyses of the crack tortuosity factor $\tau$ of all types of samples are shown in Table 5.

Table 5 Analyses of the crack tortuosity

\begin{tabular}{lcccc}
\hline Specimen No. & NC & SFRC25 & SFRC35 & SFRC55 \\
\hline 1 & 0.8905 & 0.8071 & 0.8210 & 0.6046 \\
2 & 0.8989 & 0.8107 & 0.8111 & 0.8400 \\
3 & 0.8757 & 0.8723 & 0.8475 & 0.7679 \\
4 & 0.9063 & 0.8184 & 0.6807 & 0.6543 \\
5 & 0.9434 & 0.8118 & 0.8309 & 0.8181 \\
\hline
\end{tabular}




\begin{tabular}{lcccc}
\hline 6 & 0.8770 & 0.8277 & 0.8207 & 0.7931 \\
7 & 0.9072 & 0.8395 & 0.8820 & 0.7202 \\
8 & 0.8583 & 0.8129 & 0.8477 & 0.7477 \\
9 & 0.8958 & 0.8178 & 0.8387 & 0.7662 \\
10 & 0.9321 & 0.8526 & 0.7841 & 0.7122 \\
Average, $\tau$ & 0.8995 & 0.8271 & 0.8164 & 0.7424 \\
Standard deviation, $\sigma$ & 0.0249 & 0.0214 & 0.05425 & 0.0724 \\
Coefficient of variation, CV $(\%)$ & $2.8 \%$ & $2.6 \%$ & $6.6 \%$ & $9.7 \%$ \\
\hline
\end{tabular}

From Table 5, it can be observed that the standard deviation and the coefficient of variation of $\tau$ for each types of specimen are very small, it means that the factor $\tau$ can be adopted to evaluate the crack tortuosity.

Fig.15 demonstrates the comparison of the average $\tau$ of the NC, SFRC25, SFRC35 and SFRC55 specimens.

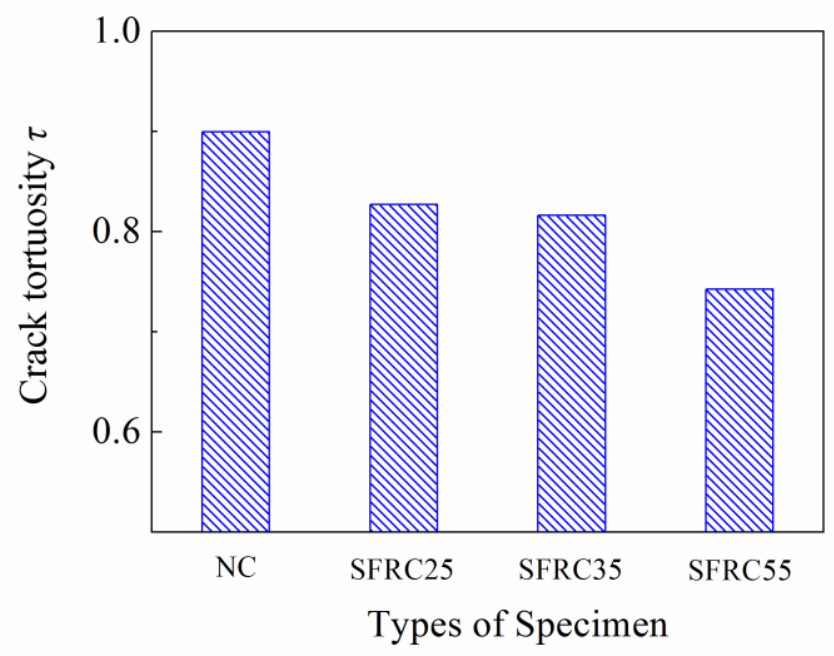

Fig.15 Comparison of the crack tortuosity $\tau$

From Fig.15 and Table 5, some phenomena as follows can be observed:

i) Compared to the NC specimen, the crack tortuosity factor $\tau$ of SFRC25, SFRC35 and SFRC55 decrease by about $8 \%, 9 \%$ and $17 \%$, respectively.

ii) Compared to the SFRC25 specimen, the crack tortuosity factor $\tau$ of the SFRC35 and SFRC55 decrease by about $2 \%$ and $10 \%$, respectively.

It means that the total crack length is affected by the addition of the steel fiber, and the crack tortuosity is increased obviously with the increasing of the fiber dosage. 
The statistical analyses of the surface roughness factor $R_{\mathrm{S}}$ of all types of samples are shown in Table 6.

Table 6 Analyses of the crack surface roughness

\begin{tabular}{lcccc}
\hline Specimen No. & NC & SFRC25 & SFRC35 & SFRC55 \\
\hline 1 & 1.1480 & 1.2591 & 1.2287 & 1.7666 \\
2 & 1.2396 & 1.2552 & 1.2953 & 1.3122 \\
3 & 1.2595 & 1.2268 & 1.3406 & 1.7282 \\
4 & 1.1734 & 1.2343 & 1.3503 & 1.5952 \\
5 & 1.1303 & 1.2429 & 1.2137 & 1.4390 \\
6 & 1.0770 & 1.1715 & 1.3172 & 1.3360 \\
7 & 1.1721 & 1.2058 & 1.3664 & 1.4335 \\
8 & 1.1296 & 1.2122 & 1.2042 & 1.6703 \\
9 & 1.1155 & 1.1977 & 1.1854 & 1.4827 \\
10 & 1.0895 & 1.2514 & 1.2741 & 1.3972 \\
Average, $R_{\text {s }}$ & 1.1534 & 1.2257 & 1.2776 & 1.5161 \\
Standard deviation, $\sigma$ & 0.0596 & 0.0285 & 0.0662 & 0.1632 \\
Coefficient of variation, CV $(\%)$ & $5.2 \%$ & $2.3 \%$ & $5.2 \%$ & $10.8 \%$ \\
\hline
\end{tabular}

From Table 6, it can be observed that the standard deviation and the coefficient of variation of the $R_{\mathrm{s}}$ for each types of specimen are relatively low.

Fig.16 illustrates the comparison of the average $R_{\mathrm{S}}$ of the NC, SFRC25, SFRC35 and SFRC55 specimens.

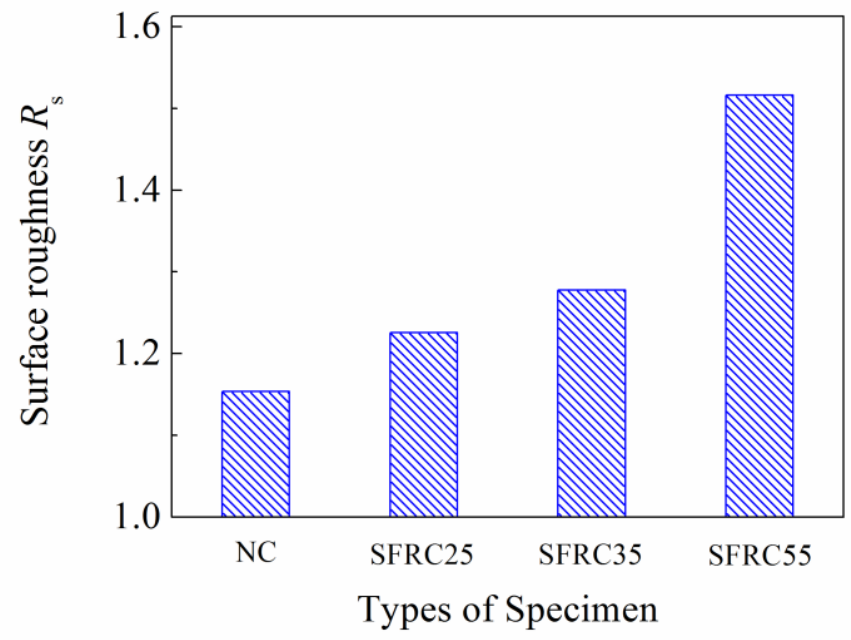

Fig.16 Comparison of the crack surface roughness $R_{\mathrm{s}}$

From Fig.16 and Table 7, it can be seen that: 
i) Compared to the NC specimen, the surface roughness $R_{\mathrm{S}}$ of the SFRC25, SFRC35 and SFRC55 increase by about $6 \%, 11 \%$ and $31 \%$, respectively.

ii) Compared to the SFRC25 specimen, the surface roughness $R_{\mathrm{S}}$ of the SFRC35 and SFRC55 increase by about $4 \%$ and $24 \%$, respectively.

The analyses above mean that the total surface area of the crack is affected strongly by the addition of steel fibers and the surface roughness factor $R_{\mathrm{s}}$ increases with the increasing of fiber content.

\section{Conclusions}

Based on the results of the investigation, the following conclusions can be drawn:

1. The post-crack behavior of the concrete is improved with the addition of macro steel fiber. The crack width of the fiber reinforced specimen is more easily to control than the specimen without any reinforcement.

2. The coefficients of the water permeability of the cracked specimens are smaller than the values predicted by the Poiseuille law. The reasons may be attributed to the tortuosity and roughness of the crack.

3. The modified Poiseuille law can be adopted to evaluate the water permeability of the cracked concrete by considering the effect of crack geometry (tortuosity and roughness). The modified factor $\xi$ is affected by the addition of macro steel fibers and decreases with the increasing of fiber content.

4. The invented laser scan set-up can be used to evaluate the crack geometry. The steel fibers demonstrate a remarkable influence on crack tortuosity and surface roughness. The crack tortuosity factor $\tau$ and surface roughness factor $R_{\mathrm{s}}$ can be used to evaluate the effect of steel fibers on the crack geometry of the concrete.

5. The addition of macro steel fibers has a positive effect on reducing water permeability of the cracked concrete. 


\section{Acknowledgements}

The authors gratefully acknowledge the National Natural Science Foundation of China, Grants: 51578109 and 51121005.

\section{References}

[1] ASTM International, Standard test method for measurement of rate of absorption of water by hydrauliccement concrete, ASTM C1585, 2013.

[2] British Standard Institution, Testing concrete method for determination of water absorption, BS 1881-122, 2011.

[3] National Standard of the People's Republic of China. Standard for test methods of long-term performance and durability of ordinary concrete, GB/T 50082, 2009.

[4] Y. Ding, Z. You, S. Jalali, Hybrid fiber influence on strength and toughness of RC beams. Compos. Struct. 2010, 92(9): 2083-2089. https://doi.org/10.1016/j.compstruct.2009.10.016

[5] S.-C. Lee, J.-Y. Cho, F. J. Vecchio, Tension-Stiffening Model for Steel Fiber-Reinforced Concrete Containing Conventional Reinforcement. ACI Struct. J. 2013, 110(4):639-648, https://doi.org/10.14359/51685749.

[6] Y. Ding, W. Kusterle, Compressive stress-strain relationship of steel fibre-reinforced concrete at early age. Cem. Concr. Res. 2000, 30(10):1573-1579, https://doi.org/10.1016/S0008-8846(00)00348-3

[7] R.S. Olivito, F.A. Zuccarello, An experimental study on the tensile strength of steel fiber reinforced concrete. Compos. Part B: Eng. 2010, 41(3):246-255, http://dx.doi.org/10.1016/j.compositesb.2009.12.003.

[8] M.N. Soutsos, T.T. Le, A. P. Lampropoulos, Flexural performance of fibre reinforced concrete made with steel and synthetic fibres. Constr. Build. Mater. 2012, 36(4):704-710, http://dx.doi.org/10.1016/j.conbuildmat.2012.06.042.

[9] X. Ning, Y. Ding, F. Zhang, et al., Experimental study and prediction model for flexural behavior of reinforced SCC beam containing steel fibers, Constr. Build. Mater. 2015, 93(15): 644-653, http://dx.doi.org/10.1016/j.conbuildmat.2015.06.024.

[10] Y. Ding, H. Liu, F. Pacheco-Torgal, et al. Experimental investigation on the mechanical behaviour of the fiber reinforced high-performance concrete tunnel segment. Compos. Struct. 2011, 93(4):1284-1289, 
https://doi.org/10.1016/j.compstruct.2010.10.006.

[11] Y. Ding, F. Zhang, T. Fernando, et al., Shear behaviour of steel fibre reinforced self-consolidating concrete beams based on the modified compression field theory, Compos. Struct. 2012,94(8): 2440-2449, http://dx.doi.org/10.1016/j.compstruct.2012.02.025.

[12] S. K. Kang, D.H. Lee, J.H. Hwang, et al., Shear behavior model for steel fiber-reinforced concrete members without transverse reinforcements. Compos. Part B Eng. 2012, 43(43):2324-2334, http://dx.doi.org/10.1016/j.compositesb.2011.11.064.

[13] N. Banthia, M. Sappakittipakorn, Toughness enhancement in steel fiber reinforced concrete through fiber hybridization. Cem. Concr. Res. 2007, 37(9):1366-1372, http://dx.doi.org/10.1016/j.cemconres.2007.05.005.

[14] F. Altun, T. Haktanir, K. Ari, Effects of steel fiber addition on mechanical properties of concrete and RC beams, Constr. Build. Mater. 2007, 21(3):654-661, http://dx.doi.org/10.1016/j.conbuildmat.2005.12.006.

[15] Y. Mohannadi, R. Carkon-Azad, SP. Singh, et al., Impact resistance of steel fibrous concrete containing fibres of mixed aspect ratio, Constr. Build. Mater. 2009, 23 (1):183-189, http://dx.doi.org/10.1016/j.conbuildmat.2008.01.002.

[16] K. T. Soe, Y. X. Zhang, L. C. Zhang, Impact resistance of hybrid-fiber engineered cementitious composite panels. Compos. Struct. 2013, 104: 320-330. https://doi.org/10.1016/j.compstruct.2013.01.029.

[17] J. Li, Y. X. Zhang, Evolution and calibration of a numerical model for modelling of hybrid-fibre ECC panels under high-velocity impact. Compos. Struct. 2011, 93(11): 2714-2722. https://doi.org/10.1016/j.compstruct.2011.05.033.

[18] Y. Ding, D. Li, Y. Zhang, et al., Experimental investigation on the composite effect of steel rebars and macro fibers on the impact behavior of high performance self-compacting concrete. Constr. Build. Mater. 2017, 136:495-505, https://doi.org/10.1016/j.conbuildmat.2017.01.073.

[19] T. Rahmani, B. Kiani, M. Shekarchi, et al., Statistical and experimental analysis on the behavior of fiber reinforced concretes subjected to drop weight test, Constr. Build. Mater. 2012, 37(12): 360-369, http://dx.doi.org/10.1016/j.conbuildmat.2012.07.068. 
[20] L. Soufeiani, S.N. Raman, M.Z.B. Jumaat, et al., Influences of the volume fraction and shape of steel fibers on fiber-reinforced concrete subjected to dynamic loading - A review, Eng. Struct. 2016, 124(1):405-417, http://dx.doi.org/10.1016/j.engstruct.2016.06.029.

[21] M. Hoseini, V. Bindiganavile, N. Banthia, The effect of mechanical stress on permeability of concrete: a review, Cem. Concr. Compos. 2009,31 (4): 213-220, http://dx.doi.org/10.1016/j.cemconcomp.2009.02.003.

[22] A. Akhavan, S.M.H. Shafaatian, F. Rajabipour, Quantifying the effects of crack width, tortuosity, and roughness on water permeability of cracked mortars, Cem. Concr. Res. 2012, 42(2):313-320, https://doi.org/10.1016/j.cemconres.2011.10.002.

[23] S.-T. Yi, T.-Y. Hyun, J.-K. Kim, The effects of hydraulic pressure and crack width on water permeability of penetration crack-induced concrete, Constr. Build. Mater. 2011, 25(5):2576-2583, https://doi.org/10.1016/j.conbuildmat.2010.11.107.

[24] K. Wang, D. Jansen, S. Shah, et al., Permeability study of cracked concrete, Cem. Concr. Res. 1997, 27 (3) : 381-393, https://doi.org/10.1016/s0008-8846(97)00031-8.

[25] C. Aldea, S. Shah, A. Karr, Permeability of cracked concrete, Mater. Struct. 1999,32(5): 370-376, https://doi.org/10.1007/bf02479629.

[26] G. Rastiello, C. Boulay, S.D. Pont, et al., Real-time water permeability evaluation of a localized crack in $\begin{array}{lllllll}\text { concrete under loading, Cem. Concr. Res. 2014, } 56 \text { (2):28, } & \text {, }\end{array}$ http://dx.doi.org/10.1016/j.cemconres.2013.09.010.

[27] J. Rapoport, C.-M. Aldea, S.P. Shah, et al., Permeability of cracked steel fiber-reinforced concrete, J. Mater. Civ. Eng. 2002,14(4):355-358, http://dx.doi.org/10.1061/(ASCE)0899-1561(2002)14:4(355).

[28] V. Picandet, A. Khelidj, H. Bellegou, Crack effects on gas and water permeability of concretes, Cem. Concr. Res. 2009,39 (6): 537-547, http://dx.doi.org/10.1016/j.cemconres.2009.03.009.

[29] R. Zimmerman, G. Bodvarsson, Hydraulic conductivity of rock fractures, Transp. Porous Media 1996,23(1) :1-30, https://doi.org/10.2172/60784.

[30] P. Dietrich, R. Helming, M. Sauter, et al, Flow and transport in fractured porous media, Springer, Berlin, 2005. 
[31] P. Stroeven, A stereological approach to roughness of fracture surfaces and tortuosity of transport paths in concrete. Cem. Concr. Compos. 2000, 22(5):331-341, http://dx.doi.org/10.1016/S0958-9465(00)00018-4.

[32] H. Xie, J. Wang, Direct fractal measurement of fracture surfaces. Int. J. Solids Struct. 1999, 36(20): 3073 3084. https://doi.org/10.1016/S0020-7683(98)00141-3.

[33] H. W. Zhou, H. Xie, Direct Estimation of the Fractal Dimensions of a Fracture Surface of Rock. Surf. Rev. Lett. 2012, 10(10):751-762, http://dx.doi.org/10.1142/S0218625X03005591.

[34] Y. Ding, Y. Zhang, A. Thomas, The investigation on strength and flexural toughness of fibre cocktail reinforced self-compacting high performance concrete. Constr. Build. Mater.2009, 23(1): 448-452, http://dx.doi.org/10.1016/j.conbuildmat.2007.11.006.

[35] A. Bentur, S. Mindess, Fibre reinforced cementitious composites. Taylor \& Francis, 2007.

[36] C. Qian, Y. Wang, B. Huang, et al., Water seepage in concrete cracks. Journal of the Chinese Ceramic Society,2009,37(12):2078-2082 (in Chinese)

[37] K. J. Shin, W. Bae, S. W. Choi, et al. Parameters influencing water permeability coefficient of cracked $\begin{array}{llllll}\text { concrete } & \text { specimens. } & \text { Constr. } & \text { Build. }\end{array}$ https://doi.org/10.1016/j.conbuildmat.2017.06.093.

[38] P. M.D. Santos, E.N.B.S. Júlio, A state-of-the-art review on roughness quantification methods for concrete surfaces. Constr. Build. Mater. 2013, 38(1):912-923, https://doi.org/10.1016/j.conbuildmat.2012.09.045.

[39] S. Murata, T. Saito, Estimation of tortuosity of fluid flow through a single fracture. J. Can. Pet. Technol. 2003, 42(12):39-45, http://dx.doi.org/10.2118/03-12-03.

[40] K.L. Apedo, C. Munzer, H. He, et al., Cement paste surface roughness analysis using coherence scanning interferometry and confocal microscopy. Mater. Charact. 2014, 100:108-119, https://doi.org/10.1016/j.matchar.2014.11.033.

[41] S. Erdem, M.A. Blankson, Fractal-fracture analysis and characterization of impact-fractured surfaces in different types of concrete using digital image analysis and 3D nanomap laser profilometery. Constr. Build. Mater. 2013, 40(40):70-76, http://dx.doi.org/10.1016/j.conbuildmat.2012.11.013. 


\section{Nomenclature}

NC plain concrete without any reinforcement

$L_{\mathrm{t}} \quad$ total crack length

SFRC25 macro steel fiber reinforced concrete with $S_{0}$ fiber dosage of $25 \mathrm{~kg} / \mathrm{m}^{3}$

SFRC35 macro steel fiber reinforced concrete with fiber dosage of $35 \mathrm{~kg} / \mathrm{m}^{3}$

$S_{\mathrm{t}} \quad$ total surface area of the crack

SFRC55 macro steel fiber reinforced concrete with fiber dosage of $55 \mathrm{~kg} / \mathrm{m}^{3}$

$\tau \quad$ crack tortuosity

$\begin{array}{llll}L_{0} & \text { projected crack length } & R_{\mathrm{s}} & \text { surface roughness }\end{array}$

$b_{\text {eff }} \quad$ effective crack width 